\title{
Optimization Method of Wavelet Neural Network for Suspension Bridge Damage Identification
}

\author{
Deqing Guan*, Jie Li and Jun Chen \\ School of Civil Engineering and Architecture, Changsha University of Science \& Technology, Changsha, China \\ ${ }^{*}$ Corresponding author
}

\begin{abstract}
In this paper, an optimization method of wavelet neural network for structure damage identification is established. The suspension bridge is used as the research object. Firstly, wavelet coefficients modulus maxima are obtained by wavelet transform to determine the location of structural damage. Then, the connection weights and thresholds of the neural network are optimized by the particle swarm optimization, the optimized neural network is constructed to determine the degree of damage of the bridge. The validity of the method is verified by numerical simulation of multi span suspension bridge.
\end{abstract}

Keywords-wavelet transform; neural network; particle swarm optimization; damage identification; suspension bridge

\section{INTRODUCTION}

Transportation is the economic lifeline of the country. And the bridge is the key component of the traffic route. However, the structure is subjected to the coupling action of various uncertain factors, which will inevitably be damaged, and the degree of damage increased with the increase of the time. In order to ensure the normal operation of the bridge in the life cycle, the damage position and degree of the bridge must be checked regularly. Because of this, how to determine structural damage location and damage degree has become the hot topic in academia and engineering.

In recent years, many scholars have carried out a series of research work on structural damage diagnosis, and have achieved good results. Wang [1] used wavelet analysis to study the transverse crack of the cantilever beam, the abrupt change of the wavelet coefficient means the local mutation of the signal, and the mutation occurs in the vicinity of the local damage. Hong [2] predicted structural damage by using wavelet transform, using the characteristics of Lipschitz index to identify the structural damage, the study found that the size of the Lipschitz index can be used as an indicator of the degree of damage. Amaravdi [3] used the curvature mode to construct the wavelet map, and then through the observation of the wavelet graph can be found the structural damage location. $\mathrm{Li}$ Bing [4] used the wavelet finite element method to establish the finite element model of the free vibration of a beam, the pros and cons of crack identification of a cantilever beam are studied in the finite element. Wu [5] used BP neural network for damage identification of building structure. The generalized rule is used to train the multilayer BP neural network, and the trained neural network has the ability to identify the damage location and degree of the individual component. Elkordy [6] established five kinds of finite element model under different damage conditions. The finite element analysis is used to obtain enough training samples, and the neural network is trained by the samples, the last, trained network has successfully identified the damage of the actual frame structure. Feng and Luo [7] used heuristic (approach Heuristics) steepest descent method to improve the convergence speed of BP neural network, and the method is verified by the damage identification of a cantilever beam.

In this paper, the method of combining wavelet transform with neural network is adopted. Firstly, wavelet coefficients modulus maxima are obtained by wavelet transform to determine the location of structural damage, then, by using the nonlinear relation between the damage degree and the modulus maxima of the wavelet coefficients, the neural network is constructed to determine the degree of damage of the suspension bridge. This method can identify the damage location and damage degree of structure damage. The validity of the method is verified by numerical simulation of multi span suspension bridge.

\section{DAMAge IDENTIFICATION PRINCIPLE}

\section{A. The Principle of Damage Location Identification}

The definition of wavelet function: if $\psi(\mathrm{t})$ is a square integrable function, that is to say $\psi(t) \in L^{2}(R)$, Its Fourier transform is $\Phi(\omega)$, If $\Phi(\omega)$ satisfies the following admissibility conditions:

$$
0<C_{\psi}=\int_{-\infty}^{+\infty} \frac{|\Phi(\omega)|^{2}}{|\omega|} \mathrm{d} \omega<\infty
$$

Then called $\psi(\mathrm{t})$ is a basic wavelet or mother wavelet.

After stretching and translating the basic wavelet, we can get a wavelet function family.

$$
\psi_{a, b}(t)=\frac{1}{\sqrt{|a|}} \psi\left(\frac{t-b}{a}\right) \quad a, b \in R, \quad a>0
$$


In the formula, a is the expansion factor, and b is the translation factor.

When the structure is damaged, the decrease of section stiffness (EI) will result in the curvature change, strain will also vary linearly with curvature. It can be known that there is a singular point at the structural damage location. According to the singularity detection theory, the local modulus maxima of the wavelet transform coefficients at the damage point. In this paper, the location of the modulus maxima of the wavelet coefficients is determined to determine the location of the damage.

\section{B. The Principle of Damage Degree Identification}

The basic principle of damage identification of the neural network structure: by numerical method or experimental method to obtain structural physical quantity as input parameters, the damage degree of structure as the output parameter, these input and output parameters form a set of training samples. Through a certain amount of training samples to train the network and the formation of memory, the nonlinear mapping between the input parameters and the output parameters can be realized, and the solution of the inverse problem can be obtained.

The neural network model of particle swarm optimization algorithm can optimize the connection weights and thresholds of the neural network. It makes up the disadvantages of the neural network for the random assignment of the connection weights and thresholds.

The calculation procedure of the neural network with particle swarm optimization is shown as follows:

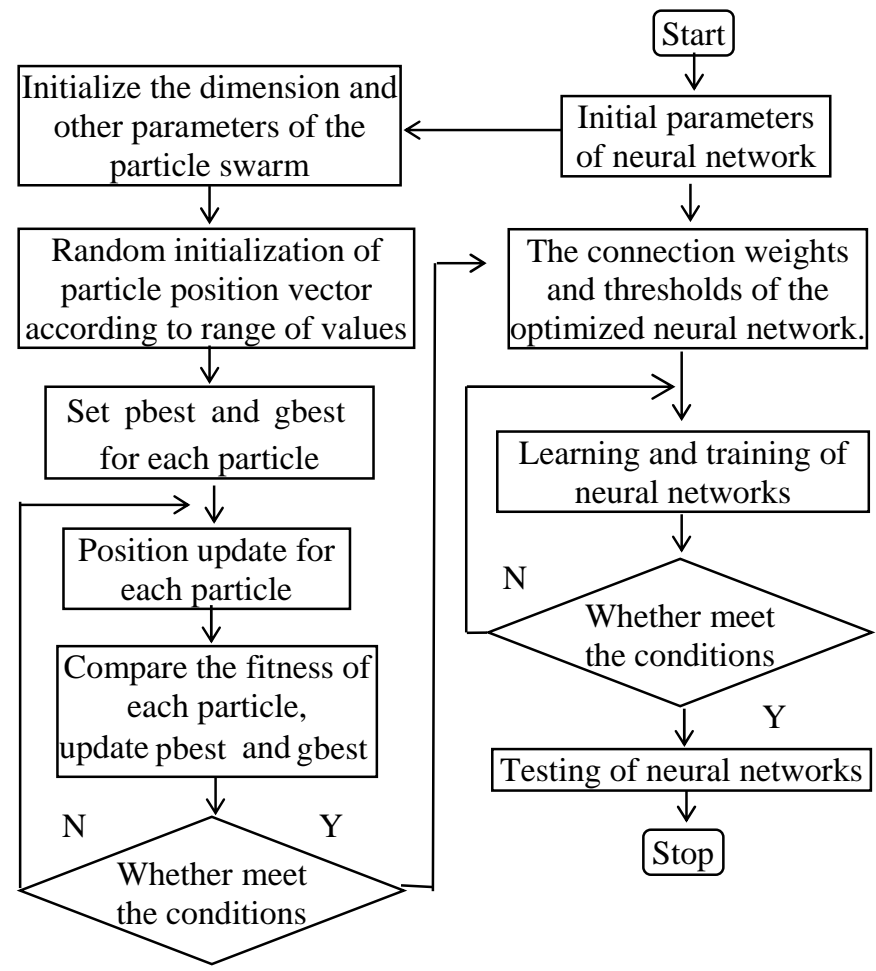

\section{NUMERICAL SiMULATION ANALYSIS}

The finite element model of the suspension bridge is shown in Figure I. The main beam element type is simulated by beam 4 , the middle span of the main beam is $120 \mathrm{~m}$, on the both side of the span is $60 \mathrm{~m}$, section size: $b \times h=3500 \mathrm{~mm} \times 2500 \mathrm{~mm}$, elastic modulus: $E=2.0 \times 10^{11} \mathrm{~N} / \mathrm{m}^{2}$, material density: $\rho=7850 \mathrm{~kg} / \mathrm{m}^{3}$, Poisson ratio: $\mu=0.3$; the main tower element type is also simulated by beam4, section size $: b \times h=3000 \mathrm{~mm} \times 3000 \mathrm{~mm}$, elastic modulus: $E=3.5 \times 10^{11} \mathrm{~N} / \mathrm{m}^{2}$, material density: $\rho=2600 \mathrm{~kg} / \mathrm{m}^{3}$, Poisson ratio: $\mu=0.167$; The main cable and boom element type are simulated by link10, elastic modulus: $E=2.0 \times 10^{11} \mathrm{~N} / \mathrm{m}^{2} \quad$ material density: $\rho=7850 \mathrm{~kg} / \mathrm{m}^{3}$, Poisson ratio: $\mu=0.3$, the main cable section size: $\pi r^{2}=0.05 \mathrm{~m}^{2}$, section size of boom: $\pi r^{2}=0.02$, boom spacing is $6 \mathrm{~m}$, multi span suspension bridge structure finite element model is divided into 354 units, the main beam is divided into 40 units, the center point spacing of each main beam element is $6 \mathrm{~m}$, the main towers and main cables are fixed with the ground.

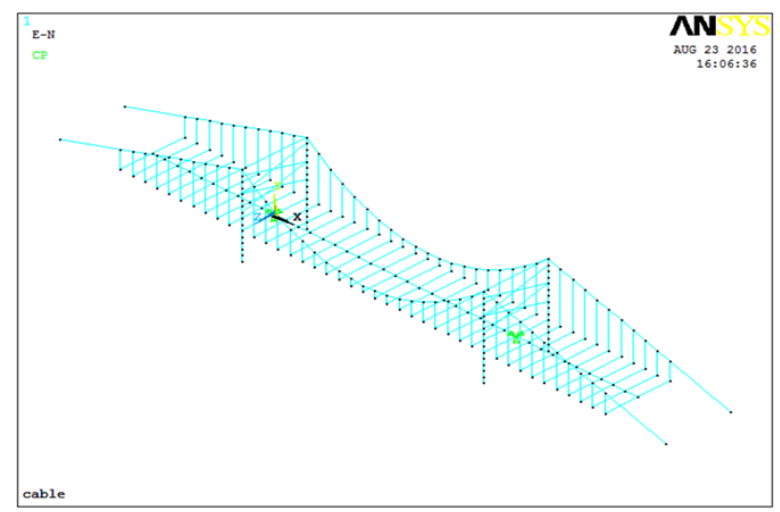

FIGURE I. FINITE ELEMENT MODEL OF SUSPENSION BRIDGE

The stiffness reduction of multi span suspension bridge girder structure unit 20 to define the damage. The suspension bridge structure model is shown in Figure II.

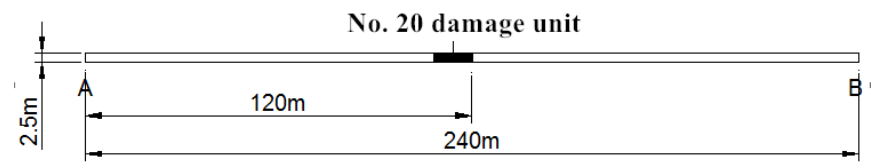

FIGURE II. STRUCTURE MODEL OF SUSPENSION BRIDGE

Firstly, wavelet analysis is used to identify the damage location of multi span suspension bridge structure. Then the neural network and neural network of particle swarm optimization are used to identify the damage degree of the suspension bridge, the effect of the two methods on the degree of damage identification is analyzed and compared. 


\section{A. Determine the Damage Location of Suspension Bridges}

The strain mode of multi span suspension bridge is obtained by the finite element analysis, and the chart of wavelet coefficient is obtained by continuous wavelet transform. We find that there is a significant discontinuity, that is, the location of the damage. Wavelet coefficient chart as shown in Figure III.

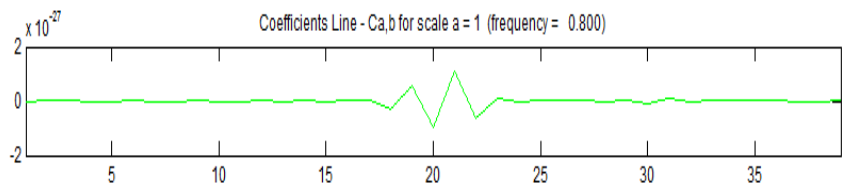

FIGURE III. WAVELET COEFFICIENT CHART

\section{B. Determine the Damage Degree of Suspension Bridges}

\section{1) Damage degree identification based on WNN}

Neural network is used to identify the structural damage degree, which needs to be trained to construct the neural network, and the training needs enough training samples. Ten sets of different damage degree are defined in unit 20, and the modulus maxima of the 10 sets of damage degree from scale one to size four are obtained by the wavelet transform. The modulus maxima are a training sample of BP neural network. The modulus maxima is shown in Table I

TABLE I. THE MODULUS MAXIMA $/ 10^{-28}$

\begin{tabular}{|c|c|c|c|c|c|}
\hline $\begin{array}{c}\text { Degree Of } \\
\text { Injury }\end{array}$ & $6 \%$ & $8 \%$ & $10 \%$ & $12 \%$ & $14 \%$ \\
\hline Scale 1 & 5.78 & 6.768 & 8.246 & 6.547 & $\begin{array}{c}20.4 \\
35\end{array}$ \\
\hline Scale 2 & 5.456 & 8.414 & 18.879 & 8.22 & $\begin{array}{c}26.4 \\
36\end{array}$ \\
\hline Scale 3 & 7.396 & 8.57 & 10.446 & 14.435 & $\begin{array}{c}43.4 \\
45\end{array}$ \\
\hline Scale 4 & 7.806 & 10.364 & 12.546 & 14.826 & $\begin{array}{c}25.8 \\
99\end{array}$ \\
\hline Degree Of \\
Injury & $16 \%$ & $18 \%$ & $20 \%$ & $22 \%$ & $24 \%$ \\
\hline Scale 1 & 9.67 & 12.723 & 24.157 & 16.531 & $\begin{array}{c}21.1 \\
32\end{array}$ \\
\hline Scale 2 & 16.623 & 18.241 & 22.345 & 20.85 & $\begin{array}{c}23.5 \\
57\end{array}$ \\
\hline Scale 3 & 20.467 & 24.53 & 32.474 & 35.78 & $\begin{array}{c}35.7 \\
6\end{array}$ \\
\hline Scale 4 & 30.143 & 22.873 & 34.656 & 40.683 & $\begin{array}{c}46.4 \\
5\end{array}$ \\
\hline
\end{tabular}

In order to study the effect of neural network training, the training results of neural network are shown in Table II. Training fitting effect diagram is shown in Figure IV:

TABLE II. THE TRAINING RESULTS OF NEURAL NETWORK

\begin{tabular}{|c|c|c|c|c|c|c|}
\hline & $\begin{array}{c}\text { Expecte } \\
\mathbf{d} \\
\text { Output }\end{array}$ & 0.06 & 0.08 & 0.1 & 0.12 & 0.14 \\
\cline { 2 - 7 } $\begin{array}{c}\text { Unit } \\
\mathbf{2 0}\end{array}$ & $\begin{array}{c}\text { Actual } \\
\text { Output }\end{array}$ & $\begin{array}{c}0.0763 \\
6\end{array}$ & $\begin{array}{c}0.0903 \\
3\end{array}$ & 0.1021 & $\begin{array}{c}0.1185 \\
5\end{array}$ & 0.14428 \\
\cline { 2 - 7 } & $\begin{array}{c}\text { Relative } \\
\text { Error }\end{array}$ & $\begin{array}{c}27.27 \\
\%\end{array}$ & $\begin{array}{c}12.91 \\
\%\end{array}$ & $2.10 \%$ & $1.21 \%$ & $3.00 \%$ \\
\hline
\end{tabular}

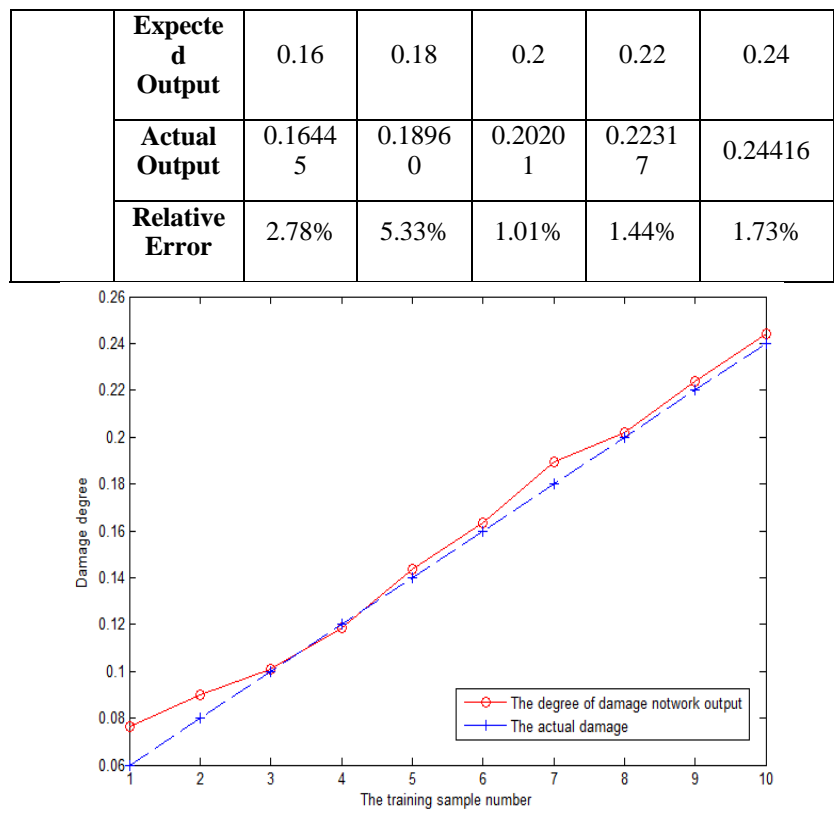

FIGURE IV. TRAINING OF FITTING EFFECT DIAGRAM

In order to verify the effect of the trained neural network to the degree of damage identification, the three groups of damage degree selected as the test sample to verify the accuracy of the neural network. Test data of neural network is shown in Table III. Test results of neural network are shown in Table IV.

TABLE III. TEST DATA OF NEURAL NETWORK/10-28

\begin{tabular}{|c|c|c|c|c|}
\hline \multirow{4}{*}{ Unit 20 } & $\begin{array}{c}\text { Degree of } \\
\text { Injury }\end{array}$ & $5 \%$ & $7 \%$ & $9 \%$ \\
\cline { 2 - 5 } & Scale 1 & 3.271 & 5.523 & 5.97 \\
\cline { 2 - 5 } & Scale 2 & 3.783 & 6.578 & 6.644 \\
\cline { 2 - 5 } & Scale 3 & 4.746 & 8.157 & 8.84 \\
\cline { 2 - 5 } & Scale 4 & 6.862 & 8.654 & 10.656 \\
\hline
\end{tabular}

TABLE IV. TEST RESULTS OF NEURAL NETWORK

\begin{tabular}{|c|c|c|c|c|}
\hline $\begin{array}{c}\text { Unit } \\
\mathbf{2 0}\end{array}$ & $\begin{array}{c}\text { Degree of } \\
\text { Injury }\end{array}$ & $5 \%$ & $7 \%$ & $9 \%$ \\
\hline & Output Result & 0.05427 & 0.07345 & 0.08405 \\
\hline & $\begin{array}{c}\text { Relative } \\
\text { Error }\end{array}$ & $8.54 \%$ & $4.93 \%$ & $6.61 \%$ \\
\hline
\end{tabular}

2) Damage degree identification based on PSO-WNN

According to the operation process of PSO-WNN, the source program is compiled in MATIAB. The global optimal solution of the particle is obtained by the source program, and the global optimal solution is taken as the connection weight and threshold value of the neural network. The model maximum data in Table1 is also used as the training sample of neural network after particle swarm optimization. The training results based on PSO-WNN are shown in Table V. The training of the fitting effect diagram is shown in Figure V. 
TABLE V. THE TRAINING RESULTS OF PSO-WNN

\begin{tabular}{|c|c|c|c|c|c|c|}
\hline & $\begin{array}{c}\text { Expected } \\
\text { Output }\end{array}$ & 0.06 & 0.08 & 0.1 & 0.12 & 0.14 \\
\cline { 2 - 7 } & $\begin{array}{c}\text { Actual } \\
\text { Output }\end{array}$ & 0.06059 & 0.07765 & 0.10106 & 0.11886 & $\begin{array}{c}0.141 \\
36\end{array}$ \\
\cline { 2 - 7 } $\begin{array}{c}\text { Un } \\
\text { it } \\
\mathbf{2 0} \\
\text { Eelative }\end{array}$ & $0.98 \%$ & $2.94 \%$ & $1.06 \%$ & $0.95 \%$ & $\begin{array}{c}0.97 \\
\%\end{array}$ \\
\cline { 2 - 7 } & $\begin{array}{c}\text { Expected } \\
\text { Output }\end{array}$ & 0.16 & 0.18 & 0.2 & 0.22 & 0.24 \\
\cline { 2 - 7 } & $\begin{array}{c}\text { Actual } \\
\text { Output }\end{array}$ & 0.16384 & 0.17888 & 0.19577 & 0.22423 & $\begin{array}{c}0.235 \\
04\end{array}$ \\
\cline { 2 - 7 } & $\begin{array}{c}\text { Relative } \\
\text { Error }\end{array}$ & $2.40 \%$ & $0.62 \%$ & $2.12 \%$ & $1.92 \%$ & $\begin{array}{c}2.07 \\
\%\end{array}$ \\
\hline
\end{tabular}

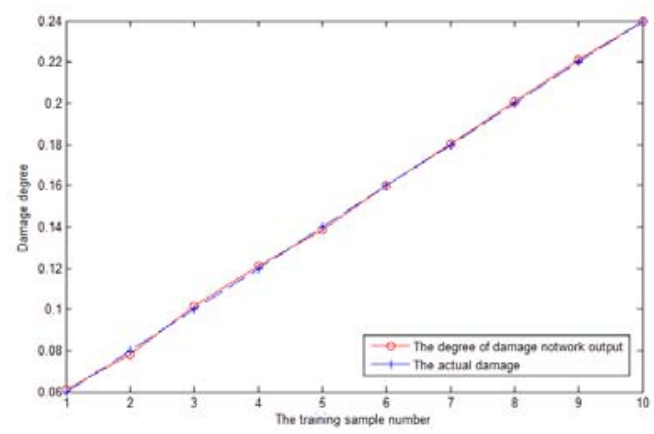

FIGURE V. TRAINING OF FITTING EFFECT DIAGRAM

In order to verify the effect of the trained neural network of particle swarm optimization to the degree of damage identification, the three groups of damage degree selected as the test sample to verify the accuracy of the neural network. Table III is also used for the test data, test results of PSOWNN are shown in Table VI

TABLE VI. TEST RESULTS OF PSO-WNN

\begin{tabular}{|c|c|c|c|c|}
\hline \multirow{2}{*}{$\begin{array}{c}\text { Unit } \\
20\end{array}$} & Degree Of Injury & $5 \%$ & $7 \%$ & $9 \%$ \\
\cline { 2 - 5 } & Output Result & 0.0489 & 0.07234 & 0.09132 \\
\cline { 2 - 5 } & Relative Error & $2.2 \%$ & $3.34 \%$ & $1.47 \%$ \\
\hline
\end{tabular}

For multi span suspension bridge damage identification from Table IV and Table VI, the error of the test results based on PSO-WNN is smaller than the error of the test results based on neural network. Therefore concluded that algorithm of PSOWNN is more accurate in the degree of damage identification.

\section{CONCLUSIONS}

1) This paper presented optimization method of wavelet neural network for structure damage identification. This method can be used to identify the damage position and damage degree of suspension bridge.

2) The method overcomes the difficulty of using wavelet analysis to identify the damage degree, and solves the problem of long calculation time and poor accuracy of using the pure neural network for damage identification.
3) The recognition accuracy of damage degree is not high from neural network. The neural network of particle swarm optimization has good effect on the degree of damage identification, and the relative error is small.

4) The validity of the identification method based on wavelet neural network is verified by numerical simulation of multi span suspension bridge. It has certain guiding significance to the engineering practical problem.

\section{ACKNOWLEDGMENT}

The work is supported by National Natural Science Foundation of China (No.51378079)

\section{REFERENCES}

[1] Wang Q., Deng X.. "Damage Detection with Sptial Wavelet” [J]. International Journal of Solids and Strucures, 1999, 36: 3443-3468.

[2] Hong J. C., Kim Y. Y., Lee H. C., etal. "Damage Detection using the Lipschitz Exponent Estimated by the Wavelet Transform: Applications to Vibration Modes of a Beam" [J]. International Journal of Solids and Structures, 2002, 39 (7): 1803-1816.

[3] Amaravadi V., Rao V., Koval L. R., etal. "Structural Health Monitoring using Wavelet Transforms” [J]. Smart structures and integrated systems, Newport beach, 2001, 4327 (3): 258-269.

[4] Li Bing., Chen Xuefeng., Hu Qiao.. "Crack Identification of Cantilever Beam Based on Wavelet Finite Element Method” [J]. Journal of Vibration Engineering, 2004, 17(2): 43-48.

[5] Wu X., Ghaboussi J., Garrett J. H.. "Junior use of Neural Networics in Detection of Structural Damage” [J]. Computers and Structures, 1992, 42 (4): 649-659.

[6] Elkordy M. F., Chang K. C., Lee G. C.. "Neural Network Strained by Analytically Simulated Damage States" [J]. Journal of Computing in Civil Engineering, 1993, 7: 130-145.

[7] Fang X., Luo H., Tang J.. "Structural Damage Detection, using Neural Network with Learning Rate Improvement” [J]. Computers and Structures, 2005, 83 (2), 2150-2161. 